\title{
Whatever Your Preference Is for the Treatment of the Proximal Humeral Fracture
}

\author{
Nam Su Cho \\ Shoulder and Elbow Clinic, Department of Orthopaedic Surgery, College of Medicine, Kyung Hee University, Seoul, Korea
}

The incidence of proximal humeral fractures in the elderly is on the rise due to increasing sports activities and incidence of osteoporosis. ${ }^{1,2)}$ Unstable and displaced proximal humeral fractures are generally accepted indications for surgeries. ${ }^{3)}$ Current treatments include osteosynthesis using proximal humeral nails and plates, tension band wiring, percutaneous or minimally invasive techniques, such as pinning, intramedullary flexible nails, and screw osteosynthesis, hemiarthroplasty, and reverse total shoulder arthroplasty. ${ }^{4-7)}$ Surgical treatment requires anatomical reduction and a stable fixation, which proves to be especially difficult in an osteoporotic bone. Unreduced or poorly reduced fractures with varus angulation of the neck-shaft angle can also be a cause of immediate postoperative failures. ${ }^{8,9)}$

With the advent of locking plates and screw fixation, a greater number of displaced proximal humeral fractures are being treated with osteosynthesis. ${ }^{10-14)}$ Although locking plates have a mechanical advantage over standard implants in osteoporotic bones, ${ }^{13,15)}$ complication rates after surgical stabilization remain high. ${ }^{11,16)}$ Several studies have reported complications, two of the most common being varus inclination and screw penetration. Gardner et al. ${ }^{13)}$ reported that a varus collapse is typically caused by rotator-cuff forces, thereby suggesting that maintaining a reduction necessitates some medial support. Other than these, loss of fixation is another frequently observed complication, and requires removal of the screws to avoid impending joint destruction in locking plates. ${ }^{17,18)}$

Fixation loss is often encountered after surgical treatment of displaced unstable proximal humeral fractures in elderly patients with osteoporosis. Despite many approaches and attempts to overcome this problem, no definitive consensus operation exists. Liew et al. ${ }^{19)}$ found screw purchase to be significantly greater when screws were placed into the medial subchondral bone, and cautioned about relying on fixation in the superior humeral head. Fixative construction should be augmented with heavy sutures wherever required, which passes adjacent to the bony fragments, goes through the rotator cuff tissue, and winds back to the fixation implant to provide maximal implant-fragment stability. ${ }^{19)}$ In other words, the displacing force of the rotator cuff must be reduced through additive fiber cerclages. We have previously reported the effects of additive augmentation sutures in proximal humeral fractures stabilized by locking plates. ${ }^{20)}$ Our results show that the loss of neck-shaft angle was greater in patients who did not receive additive augmentation sutures than in patients who received it. Thus, in cases of severe dislocation or comminution of the fracture (especially in elderly patients with concomitant osteoporosis), we believe that making additive trans-cuff sutures after internal fixation provides a sturdier fixation.

An article by Min et al. ${ }^{21)}$ evaluated the clinical and radiologic results between the periarticular proximal humerus locking plate and Polarus nail for displaced proximal humerus fractures. The overall results showed no significant difference in the clinical outcomes between the plate and nail. However, in the nail group, the rate of failure to maintain reduction during the 1-year period after surgery was significantly higher than in the plate group. In addition, when comparing the plate groups based on with or without the medial support, the presence of medial support was found to be beneficial in maintaining the fracture reduction and bone union rate.

The choice of surgical treatment for proximal humeral fracture is irrelevant. Whatever the preference, the priority is to maintain the surgical principles. It is important to remember that treatment of proximal humeral fractures is a balancing surgery that not only treats the fracture piece, but also obtains the initial mechanical support of the medial calcar and neutralizes the

\section{Correspondence to: Nam Su Cho}

Department of Orthopaedic Surgery, Kyung Hee University Hospital at Gangdong, College of Medicine, Kyung Hee University, 892 Dongnamro, Gangdong-gu, Seoul 05278, Korea

Tel: +82-2-440-6154, Fax: +82-2-440-7498, E-mail: nscos1212@empas.com

Editorial does not need an IRB approval.

Financial support: None. Conflict of interests: None. 
forces of the surrounding rotator cuff tissue. If the fundamentals are clearly upheld, good results are logically expected.

\section{References}

1. Palvanen M, Kannus P, Niemi S, Parkkari J. Update in the epidemiology of proximal humeral fractures. Clin Orthop Relat Res. 2006;442:87-92.

2. Court-Brown CM, Caesar B. Epidemiology of adult fractures: a review. Injury. 2006;37(8):691-7.

3. Neer CS 2nd. Displaced proximal humeral fractures. I. Classification and evaluation. J Bone Joint Surg Am. 1970;52(6):107789.

4. Cornell CN. Tension-band wiring supplemented by lag-screw fixation of proximal humerus fractures: a modified technique. Orthop Rev. 1994;Suppl:19-23.

5. Hintermann B, Trouillier HH, Schäfer D. Rigid internal fixation of fractures of the proximal humerus in older patients. J Bone Joint Surg Br. 2000;82(8):1107-12.

6. Jaberg H, Warner JJ, Jakob RP. Percutaneous stabilization of unstable fractures of the humerus. J Bone Joint Surg Am. 1992;74(4):508-15.

7. Schippinger G, Szyszkowitz R, Seibert FJ. Current concepts in the treatment of proximal humeral fractures. Curr Orthop. 1997;11(3):203-14.

8. Robinson CM, Amin AK, Godley KC, Murray IR, White TO. Modern perspectives of open reduction and plate fixation of proximal humerus fractures. J Orthop Trauma. 2011;25(10):618-29.

9. Aggarwal S, Bali K, Dhillon MS, Kumar V, Mootha AK. Displaced proximal humeral fractures: an Indian experience with locking plates. J Orthop Surg Res. 2010;5:60.

10. Plecko M, Kraus A. Internal fixation of proximal humerus fractures using the locking proximal humerus plate. Oper Orthop Traumatol. 2005;17(1):25-50.

11. Agudelo J, Schürmann M, Stahel $P$, et al. Analysis of efficacy and failure in proximal humerus fractures treated with locking plates. J Orthop Trauma. 2007;21(10):676-81.
12. Gardner MJ, Lorich DG, Werner CM, Helfet DL. Secondgeneration concepts for locked plating of proximal humerus fractures. Am J Orthop (Belle Mead NJ). 2007;36(9):460-5.

13. Gardner MJ, Weil Y, Barker JU, Kelly BT, Helfet DL, Lorich DG. The importance of medial support in locked plating of proximal humerus fractures. J Orthop Trauma. 2007;21(3):185-91.

14. Rose PS, Adams CR, Torchia ME, Jacofsky DJ, Haidukewych GG, Steinmann SP. Locking plate fixation for proximal humeral fractures: initial results with a new implant. J Shoulder Elbow Surg. 2007;16(2):202-7.

15. Edwards SL, Wilson NA, Zhang LQ, Flores S, Merk BR. Twopart surgical neck fractures of the proximal part of the humerus. A biomechanical evaluation of two fixation techniques. J Bone Joint Surg Am. 2006;88(10):2258-64.

16. Südkamp N, Bayer J, Hepp P, et al. Open reduction and internal fixation of proximal humeral fractures with use of the locking proximal humerus plate. Results of a prospective, multicenter, observational study. J Bone Joint Surg Am. 2009;91(6):1320-8.

17. Schliemann B, Siemoneit J, Theisen Ch, Kösters C, Weimann A, Raschke MJ. Complex fractures of the proximal humerus in the elderly: outcome and complications after locking plate fixation. Musculoskelet Surg. 2012;96 Suppl 1:S3-11.

18. Jost B, Spross C, Grehn H, Gerber C. Locking plate fixation of fractures of the proximal humerus: analysis of complications, revision strategies and outcome. J Shoulder Elbow Surg. 2013;22(4):542-9.

19. Liew AS, Johnson JA, Patterson SD, King GJ, Chess DG. Effect of screw placement on fixation in the humeral head. J Shoulder Elbow Surg. 2000;9(5):423-6.

20. Cho NS, Shim HS, Lee SH, Jeon JW, Rhee YG. Efficacy of additive trans-cuff augmentation sutures for proximal humeral fractures stabilized by locking plates in elderly patients. Clin Should Elbow. 2015;18(2):68-74.

21. Min YK, Lee SJ, Gwak HC, Kang SW, Suh KT. Clinical and radiologic results comparing the periarticular proximal humerus locking plate and Polarus nail for displaced proximal humerus fractures. Clin Shoulder Elbow. 2017;20(4):208-16. 